\title{
Playing the Hiring Game: Class-Based Emotional Experiences and Tactics in Elite Hiring
}

\author{
PHOEBE K. CHUA, University of California, Irvine, USA \\ HILLARY ABRAHAM, University of California, Irvine, USA \\ MELISSA MAZMANIAN, University of California, Irvine, USA
}

\begin{abstract}
While studies have shown that graduates from elite universities enjoy high employment rates, they do not tell the story of how students from different social class backgrounds experience the hiring process. We address this question by interviewing upper-middle-class (UMC) and working- and middle-class (WMC) Computer Science Ph.D. students at prestigious universities who are applying for lucrative internships at established technology companies. We find that while these students are aware of and have access to the "same" resources (e.g., social connections and insider knowledge about employers' expectations), the tactics they use to act on these resources and their emotional experience of the hiring process vary along social class lines. In short, the class-based norms of UMC applicants align with those of employers. The majority of WMC applicants, however, discuss experiencing tension between their class-based norms and employers' dominant values. In contrast to their UMC counterparts, these applicants report spending substantial amounts of time preparing for the hiring process and describe the hiring process as emotionally draining. This research provides insight into the emotional burdens facing even the most privileged WMC applicants. Our findings also have implications for how organizations should take into account social class backgrounds in their hiring practices.
\end{abstract}

CCS Concepts $\bullet$ Social and professional topics $\sim$ Professional topics $\sim$ Computing profession Employment issues.

KEYWORDS: Technology companies; hiring; applicants; social class background; emotions; tactics

\section{ACM Reference Format:}

Phoebe K. Chua, Hillary Abraham, and Melissa Mazmanian. 2021. Playing the Hiring Game: Class-Based Emotional Experiences and Tactics in Elite Hiring. In PACM on Human-Computer Interaction, Vol. 5, CSCW2, Article 392, October 2021. ACM, New York, NY, USA. 27 pages, https://doi.org/10.1145/3479536.

\section{INTRODUCTION}

Finding and securing employment involves navigating ambiguity and uncertainty. Elite universities (i.e., top 25 in the U.S.) attempt to ease students' burdens by providing extensive resources to strengthen their job applications. For example, elite institutions provide tailored career guidance, extensive industry partnerships, and robust alumni networks. Given that

Authors' addresses: Phoebe K. Chua, Hillary Abraham, Melissa Mazmanian, Department of Informatics, University of California, Irvine, CA, USA, \{kychua, hillarya, mmazmani\}@uci.edu

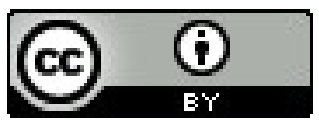

This work is licensed under a Creative Commons Attribution International 4.0 License.

(c) 2021 Copyright held by the owner/author(s).

2573-0142/2021/10-ART392. https://doi.org/10.1145/3479536 
research has shown that leveraging such resources shapes hiring outcomes [16,28,41], management researchers commonly focus on the role that elite institutions play in producing positive hiring outcomes, often assessing job applicants from top universities as a homogenous group [2,25]. Similarly, while sociologists look closely at how social class background affects educational opportunities, this research tends to make educational attainment the end goal $[31,32,44]$.

These studies do not examine whether attendance of an elite institution is enough to level the playing field for prestigious occupations. Thus, this research asks whether working- and middleclass (WMC) students receive exposure to the same resources (e.g., alumni networks, social connections, and awareness of the tacit "rules of the hiring game") as their upper-middle-class (UMC) peers. If so, are WMC students equally able to act on this knowledge?

To address these questions, we interviewed UMC and WMC Ph.D. students in Computer Science who were in the process of applying for computer science research and software engineering internships at top-tier technology companies. All applicants in our study were attending prestigious doctoral programs that served as feeder schools to top tech companies.

As sociologist Jack notes [31], both scholars and society assume that these students have "made it." Our findings suggest that this belief is true to some degree. We find that all applicants, regardless of social class background, display an understanding of the tacit expectations surrounding the hiring process. First, applicants emphasize the value of reaching out to social networks when finding open positions and learning about the desired criteria of the hiring team. Second, applicants described the importance of being collegial and collaborative with the interviewers during the interviews. However, we find that applicants' emotional responses to these expectations vary substantially. We further find that these differences can be traced to classbased values. In line with past sociological works on social class [11,36], our data suggest that the majority of UMC applicants embrace the value of being at ease with crossing social hierarchy, while most WMC applicants adopt the value of deferring to social hierarchy. Lastly, we find that emotional experiences shape the tactics that applicants engage when applying for prestigious internships. Not surprisingly, both the emotional experiences and tactics used in the hiring process were less onerous to UMC applicants.

Importantly, there were no quantitative differences in internship offers between UMC and WMC applicants in these data, indicating that both UMC and WMC tactics worked to achieve successful hiring outcomes. However, UMC and WMC applicants experience the hiring process differently, with UMC applicants reporting that they spend less time, energy, and emotional labor applying for jobs. Thus, our study demonstrates how hiring practices are rooted in class-based expectations, and WMC applicants are expected to develop strategies that fit UMC cultural norms, even if these strategies do not align with their social class background and are thus challenging to enact.

By analyzing our interview data alongside prior sociological literature, we contribute an added understanding of how socioeconomic structures underlie applicants' disparate emotional and practical experiences during the hiring process. Our findings add nuance to CSCW and sociological research on hiring $[14,17,41,46]$. We show that applicants' experiences are not only shaped by their access to social and cultural resources-such as social connections and knowledge about tacit hiring expectations-but also by their class-based values that influence their use of these resources. Our findings also have implications for how designers of social networking sites could enable WMC applicants to leverage their social capital more easily in ways that align with their class-based norms. Finally, given that many CSCW community members are university 
administrators, educators, or hiring decision-makers at companies that valorize UMC norms, we provide strategies for these groups to help relieve the additional emotional taxes that WMC applicants pay when trying to secure elite employment.

\section{RELATED WORK}

\subsection{The Role of Elite Universities in Enabling Applicants to Secure Prestigious Jobs}

Sociologists who study hiring often characterize elite universities as springboards for students to secure professional employment at prestigious firms [5,6,16,28,42]. Past scholarship consistently finds that once students from a less-privileged social class background get admitted into an elite university, they can better compete with their more privileged counterparts for jobs $[5,16]$. Such work finds that these institutions provide students with the cultural and social resources they need to meet interviewers' hiring expectations. These resources also give students a competitive edge over their peers at non-elite universities [5,16,28,42].

Previous studies have shown that employers emphasize educational prestige when making hiring decisions $[9,34,41]$ and highlight how elite institutions can give students valuable access to insider information and support through influential alumni groups and partnerships with top firms $[5,28,41,42]$. For example, given that prestigious firms want to attract candidates from elite universities, these firms often invest heavily in on-campus recruitment activities. By organizing numerous informational sessions, interview preparation workshops, and networking events, Human Resources professionals and recent alums provide students with personalized support $[5,28,41,42]$. Such support can come in the form of coaching students on what to do and say during interviews, offering an inside look into the company's ongoing work and future directions, and vouching for them through strong referrals. Scholars find that these forms of support play a critical role in increasing students' chances of being hired at prestigious firms $[16,28,41]$.

In sum, we know that elite educational institutions are generally successful in creating robust pathways for their students to enter prestigious workplaces. Understanding these mechanisms is a key contribution of prior work. However, less attention has been paid to the individual experience of capitalizing on these resources and learning to operate within elite institutional environments. Therefore, it is critical that scholars look deeper into the lived experience of the job search and not assume that all students will have the same experiences leveraging the provided resources and navigating elite hiring contexts.

\subsection{Potential Social Class Differences in How Applicants Navigate and Experience the Hiring Process}

Taking the perspective of employers, sociologists have shown that social class background can affect hiring outcomes in prestigious occupations [35,42]. However, receiving a job offer does not capture applicants' lived experiences during the hiring process. Given that the hiring context is similar to a classroom setting in that both involve engagements with authority figures (i.e., interviewers and teachers), we turn to past sociological works on educational attainment and social class background to understand how class-based values can shape interactions with people in positions of power $[11,37,44,46]$. In particular, scholars assert that UMC families often value "an assumption of equality with others" [44], whereas WMC families generally value "an awareness of social hierarchy" [44]. This work traces the influence that class-based values have on the ways that pre-college students engage in the classroom. 
To start, previous sociological studies reveal that students' willingness to leverage social connections in school varies across social class lines $[10,11,46]$. Through an ethnographic study of parents and elementary school children from different social class backgrounds, Calarco finds that class-privileged parents often encourage their children to view authority figures (e.g., teachers and coaches) as equals and expect them to feel comfortable asking for help with school-related problems $[10,11]$. These parents also teach their children to feel at ease with engaging in helpseeking behavior by asking direct questions like "Can you help me?" Calarco shows that less classprivileged parents instead motivate their children to be respectful of authority figures' time and energy, coaching them to be hardworking and independent when solving problems $[10,11]$. They also guide their children to use indirect help-seeking tactics, such as saying, "I don't get this," and waiting for the teacher to respond. Calarco illuminates that in alignment with their parents' lessons, children largely adopt their parents' class-based values and strategies concerning helpseeking. Researchers also find that these class-based differences in seeking assistance continue to exist at Ph.D.-level programs [46]. Specifically, Warnock and Appel's survey of Ph.D. students shows that class-privileged students are more likely than their less class-privileged counterparts to ask connections for help [46].

Sociologists of education also find that class-privileged parents often coach their children to express themselves freely and to demonstrate conversational ease when engaging with authority figures such as teachers $[11,37,44]$. By contrast, parents from less class-privileged backgrounds largely socialize their children to show respect and deference to people in positions of power when interacting with them $[11,37,44]$.

This body of sociological literature illuminates the ways in which students' social class backgrounds affect how they seek help and engage with authority figures [11,37,44,46]. While these studies were conducted in the school setting, it is plausible that these findings can be extended to other contexts involving evaluations and interactions with authority figures, including the job search process.

\subsection{CSCW and HCI Studies on Applicants' Experiences of the Hiring Process}

CSCW and HCI scholars have examined applicants' experiences of finding and obtaining employment. These scholars often focus on how resource-constrained groups apply for low-skill, low-status jobs. Such under-resourced groups include low-income $[18,20,31,47]$ and homeless $[27,48,49]$ individuals with limited education, financial resources, professional connections, and institutional support (e.g., access to job fairs and networking events). Prior research provides a rich understanding of how under-resourced applicants use job search platforms, social media, and personal connections to identify job openings [20,29,47]. At the same time, scholars uncover the challenges that these job seekers face when needing to demonstrate the skills, credentials, and referrals that employers expect $[19,39,48,49]$.

While this literature has paid less attention to how elite populations look for prestigious jobs, some work in ACM has looked at how applicants with more resources apply for a wider range of occupations [3,4,26]. This scholarship largely focuses on applicants from non-elite universities who lack insider resources, such as individualized attention from company employees [4,26]. Without these resources, applicants are confused about how to prepare for interviews. As a result, they report feeling more stressed, and they performed worse than those with access to such resources. However, generally missing in CSCW, HCI, and ACM scholarship-as well as the broader literature on sociology and hiring-is an investigation of how applicants with high 
educational levels (i.e., advanced degrees) and strong structural support from elite universities navigate prestigious labor markets.

\section{METHODS}

\subsection{Data Collection}

To understand the experience of Ph.D. students at elite universities applying for internships at top technology companies, we interviewed 31 applicants twice-once during their internship interview process and once after they completed the process-for a total of 60 interviews (one applicant opted out of the second interview due to their busy schedule). All applicants attended top universities and were applying for positions at elite technology companies in the U.S. The Institutional Review Board (IRB) of the authors' university reviewed and approved the study's procedures.

The focus on Ph.D. students at elite universities provides a fruitful lens to analyze the experiential and cultural differences between students from distinct social class backgrounds. As sociologists assert [36,42], such differences are highly salient when comparing groups with similar levels of skills, credentials, and access to social resources. In alignment with how social class theorists commonly define social class background [11,37,45], we identified students' social class background based on their parents' educational level and occupational status. These theorists argue that parents' educational level and occupational type heavily influence their parenting styles and their family's socioeconomic structure, which then fosters particular class-based values and norms in their children $[11,37,45]$. In line with prior work, we categorized students with a parent who has at least a master's degree and a professional or managerial occupation as uppermiddle-class (UMC). We labeled students who did not meet these criteria as working- and middleclass $(\mathrm{WMC})^{1}$. In addition, we chose to only interview applicants who grew up in the U.S. in order to focus on how this country's structural differences influence applicants' experiences and tactics around applying for jobs [11,32].

We recruited students from the top 10 feeder universities for elite technology companies; these universities were also ranked among the top 25 in the U.S. We obtained these students' emails through their universities' online directories and sent them the study invitation. For universities that did not publicly list their students' emails, we asked their CS graduate chairs to forward our recruitment materials to their students. Next, we scheduled interviews with students who confirmed that they had completed an internship interview with a technology company.

Our participants were from nine elite universities. Almost all of them were second-, third-, or fourth-year students with equal distribution across the number of years in the Ph.D. program. Students had a range of zero to four years of previous full-time work experiences, with the mean being less than one year. We detail the gender and racial/ethnic breakdown of our participants in Table 1.

Table 1. Gender and racial/ethnic composition of participants

Upper-middle-class $(\mathrm{n}=15) \quad$ Working- and middle-class $(\mathrm{n}=16)$

\footnotetext{
${ }^{1}$ We included working- and middle-class participants in the same group for two reasons. First, as we had a very small number of working-class participants, this choice enables us to protect the participants' anonymity and confidentiality. Second, the patterns in the data seemed to follow the lines of upper-middle-class and working- and middle-class groups.
} 


\begin{tabular}{lll}
\hline Gender & Female (6), Male (9) & Female (6), Male (9), Non-binary (1) \\
Race/ethnicity & Asian (4), Hispanic (1), White (10) & Asian (1), Black (1), Hispanic (1), White (13)
\end{tabular}

The first author interviewed the participants between December 2019 and May 2020. Most of the interviews happened before the COVID-19 outbreak in the U.S., and almost all participants reported that their internship search was unaffected by the pandemic-related hiring freezes. Both UMC and WMC applicants had similar internship offer rates; approximately $87 \%$ of applicants from each group secured an offer. The similar hiring outcomes across groups allow us to shed light on the differing subjective experiences and invisible work that equally qualified and successful candidates go through during a job search.

The first author conducted semi-structured interviews over a video call on Zoom. Interviews lasted approximately an hour, and participants received a \$25 Amazon gift card. Participants were aware that the interviewer was in a separate but related field and could not influence their internship search process. The interviewer also assured all participants that their responses would be kept confidential and anonymous. While social desirability bias is inherently present in all conversations, we feel that these steps minimized the chance of social desirability bias skewing our results.

During these semi-structured interviews, the first author explained to the participants that the study aims to understand their experiences of learning about and applying for internships. In order to avoid priming participants' responses, the first author did not mention the paper's interest in exploring the potential social class differences in how applicants experience the hiring process. After briefing the participants about the study's goal, the first author asked participants open-ended questions and then focused on the topics that seemed most salient to the participant. The interviews explored topics such as the following: what approaches and accomplishments participants thought mattered most for getting an offer; how they prepared for the interviews; how they felt about the hiring process; where their particular application tactics and feelings about the hiring process came from (e.g., educational experiences or familial upbringing); what were the most rewarding and least favorite parts of the interviews; and what roles they thought their Ph.D. program, university, and family upbringing played in the hiring process. Examples of interview questions include: "How do you think your interviews went?"; "What is your least favorite part about the interviews?"; and "How did you go about preparing for them?" To explore how participants make sense of the ways in which their family upbringing figured into their application experiences, the first author asked the following question at the end of the interviews: "In your opinion, how has your family upbringing influenced your approach and abilities to do well in the internship hiring process?”

\subsection{Internship Interviews at Large Tech Companies}

Most applicants go through multiple stages of interviewing for elite internships at technology companies, including a behavioral interview and a coding (or technical) interview. Interviewers primarily use behavioral interviews to assess applicants' relevant experiences, interests in the position, and approaches to various work-related situations [42]. They largely use coding interviews to evaluate applicants' technical skills for software engineering-related positions [38]. According to industry leaders, during coding interviews, applicants are expected to verbalize their thought process, use the interviewer as a problem-solving partner, and demonstrate applied knowledge learned from school [38]. While relying on interviewers and displaying technical 
competence seem like conflicting expectations, they work in concert. That is, the coding interviews attempt to assess both what candidates know and how they might collaborate with colleagues to solve complex problems.

\subsection{Data Analysis}

We conducted an inductive thematic analysis of the interview data [7]. After the first author conducted all the interviews, the first and second authors independently coded the interviews, line-by-line, using inductive open coding. At the beginning of the coding process, the first and second authors coded several transcripts and then met to develop and refine the codebook collaboratively. These authors repeated this process four times. Once they clearly defined the codebook, the first and second authors coded the rest of the transcripts independently. When the two authors had disagreements in coding, they asked the third author to act as an impartial arbitrator. Throughout the data analysis process, the first and second authors wrote memos to identify potential themes and interesting aspects of the data. All three authors met weekly over five months to discuss the data, memos, and emerging themes. ${ }^{2}$ To address emerging questions that occurred during these meetings, all authors would reread the relevant interview transcripts and revise the thematic memos.

During the first round of coding, we were interested in understanding what applicants considered to be factors that drive hiring outcomes. With this goal in mind, we generated initial codes such as, "social connections," "informational interviews," "conversational ease," "confidence," and "technical skills." When writing analytical memos, we found that in addition to technical competence, applicants across the board referred to two additional-and more subtle-hiring expectations they had become aware of during their Ph.D. program: a willingness to leverage social connections and a demonstration of collegiality and collaboration during interviews.

We then took a closer look at how applicants described enacting these two hiring expectations. With regard to relying on social ties, we paid attention to whom they reached out to and how. Examples of codes include: "cold emailing potential hiring managers," "asking advisors for introductions," and "chatting with representatives at recruitment events." We also took note of their reported emotions when using their support-seeking tactics and created codes such as "comfortable," "awkward," and "bothersome." Regarding a display of confidence and conversational ease when interacting with interviewers, we looked at applicants' descriptions of engagement styles, generating codes like "casual," "humorous," "polite," and "formal." We also used codes such as "confident," "stressed," and "nervous" to capture applicants' expressed emotions.

Drawing on these codes, we created a profile for each participant that summarized the tactics they used to meet the two key hiring expectations and their emotional experiences with the use of each tactic. These profiles enabled us to get a comprehensive picture of each participant's experience. Using these profiles, we compared how UMC and WMC applicants responded, both emotionally and practically, to hiring expectations. During this analysis, it became clear that applicants' emotional responses to the tacit expectations and their resulting application tactics varied along social class lines.

Next, we created the following subthemes to capture applicants' class-based tactics: "proactive reliance on connections," "respectful reliance on connections," "display of social ease with

\footnotetext{
${ }^{2}$ All three authors are women who grew up in middle- to upper-middle-class families. Our varied social class backgrounds gave us an insider perspective to the lived experiences of both UMC and WMC participants.
} 
interviewers," and "display of respect to interviewers." The titles of these subthemes emerged inductively from the data. Finally, we analyzed applicants' descriptions of the role their familial upbringing played in their internship search. Participants often discussed how their upbringing influenced their sense of what they considered to be appropriate ways of interacting with people in power. These musings supported-and added nuance-to our emerging insight that class-based values affect application tactics and experiences. We then grouped the subthemes under the themes: "ease with crossing social hierarchy" and "deference to social hierarchy."

At 25 participants, we noted the repetition of core themes and felt that we had begun to reach theoretical saturation. However, we continued to code and analyze the remaining transcripts to ensure that we had captured all the themes that might have emerged from the data. After we were done analyzing the data, we reviewed sociological literature on educational attainment and social class, and we observed that our findings resonated with prior insights about students' class-based values and tactics in the school setting. Thus, our definitions of UMC and WMC values emerged from a strong alignment between our inductive data analysis and findings from prior sociological literature.

\section{RESULTS}

These data suggest that all students in top Ph.D. programs are aware of the two tacit hiring expectations that employers view as critical to getting elite internships: (a) willingness to leverage social connections and (b) demonstration of collegiality and collaboration. These expectations valorize the UMC value of engaging comfortably across social hierarchy. As a result, we found that the job application process in elite hiring contexts can lead to emotional and temporal burdens on WMC applicants when these applicants feel pressure to enact values inconsistent with their upbringing in order to succeed.

\subsection{Willingness to Leverage Social Networks}

We found that all applicants understand that reaching out to social connections is valuable for finding open positions, learning what a hiring team is looking for, and getting referrals - though many said it was unfortunate that the system was set up in such a way. As Julie ${ }^{3}$, a UMC applicant, described:

"It's unfortunate because people who get interviews tend to be those who know this process, who are well connected. There are equally talented people, like my friends who are applying and sending resumes into the void but not getting interviews because they either didn't know this approach or weren't well connected enough to know it and take advantage of it. For example, it's a lot harder if you don't go to a school where recruiters come or has a lot of alumni at companies you're interested in.” - Julie (UMC, female)

Julie referenced a common assumption of the hiring process: the lack of social connections prohibits less-connected applicants from finding employment at elite companies. While this assumption has merit and is likely a bottleneck in some hiring processes, in our sample of applicants from elite institutions, none reported that they lacked access to valuable social connections. In addition, none displayed a lack of awareness that reaching out to social connections is expected and advantageous. Rather, we see class-based divisions in applicants'

\footnotetext{
${ }^{3}$ We used participant pseudonyms throughout the paper to ensure participants' anonymity and confidentiality.
} 
emotional response to the expectation to be willing to leverage social connections. This emotional response led to different tactics among UMC and WMC applicants.

\subsubsection{Upper-Middle-Class Applicants: Ease with Relying on Connections}

Across the board, the responses of UMC applicants reflect that they are at ease with crossing social hierarchy. We observe that this value manifests in their reported comfort with reaching out to individuals at target companies to learn more about available internship opportunities. These applicants described their ease with cold emailing professionals (i.e., contacting professionals with whom applicants had no direct social ties), networking at conferences, and asking connections to set up informational interviews about upcoming positions. Almost all UMC applicants described reaching out to both close and distant connections-such as advisors, friends, friends-of-friends, acquaintances, and even strangers-at the company as low-risk and rewarding. As a result, these applicants reported gaining substantial insider information about hiring teams' needs, thus allowing them to pitch their research interests in ways that interviewers view as a good "fit" for the team.

Most UMC applicants described cold emailing individuals as particularly valuable. Kyle explained:

"I'm a really big fan of cold emailing people. It's the lowest cost, highest return thing you can do, and I've been doing it since I was in high school." - Kyle (UMC, male)

Kyle's degree of comfort with cold emailing is worth noting, and it aligns with the perspective of the majority of UMC applicants. In general, these participants did not perceive reaching outside their immediate social networks and cold contacting potential hiring managers as overstepping social bounds.

Strikingly, like Kyle, the majority of UMC applicants described feeling at ease when reaching out to prospective employers. When asked where this ease comes from, UMC applicants generally cited their upbringing. Broadly, these applicants described how their parents taught them the lowrisk, high-reward nature of contacting people in authority (e.g., teachers, industry insiders, etc.) for information about various opportunities. Kyle reflected on how his parents guided him toward this tactic:

"The main reason that I'm comfortable cold emailing people is because I've always heard my parents say: 'You should always email people who are in a higher position of power. There's no downside.' And they do it. I've learned to agree that yeah, there's really no downside." - Kyle (UMC, male)

Consistent with prior research on UMC norms around support-seeking [11,44], many UMC applicants in our study explained that their parents often encourage them to ask people in higher positions of power for help in various contexts, such as navigating schools, employment opportunities, and workplaces. In light of their parents' coaching, these applicants reported capitalizing on this support-seeking tactic from an early age. As a result, UMC applicants described having a sense of ease with reaching out to both close connections (i.e., friends, colleagues, and professors) and distant contacts (i.e., acquaintances and strangers with potential overlapping work interests).

The majority of UMC applicants explained using their connections and informational interviews to find internship opportunities that align with their interests. For example, Julie described her general internship search process: 
"I'd do coffee chats [to learn more about the position].....Nine times out of ten, it stopped after the coffee chat....It was great to chat, but I'm not interested. Then the rest of the time it's helpful for figuring out what they're looking for. That helps when I'm interviewing." - Julie (UMC, female)

Julie's comments illustrate a common UMC application tactic. Rather than begin with a formal online application, applicants reach out to those in their personal networks to help forge connections at companies of interest. Then, they contact these connections for informational interviews (i.e., casual conversations about their work experiences and job opportunities). These brief, low-expectation chats happen outside of the official hiring process and serve to introduce applicants to the position and the company. By setting up informational interviews, almost all UMC applicants described being able to screen out what they see as uninteresting or irrelevant internships before officially applying. Such conversations also inform applicants' understanding of what the company looks for in candidates. When asked where she learned this application tactic, Julie credited her mother:

"[My mom] is a hiring manager and I learned it from her. She ingrained in me the importance of personal connections. She'll say things like: 'Get coffee with people at companies you're interested in. Not in a 'get me a job' way, but just asking what their company is doing, so you know if it's a good fit for you and what kinds of people they're hiring.' - Julie (UMC, female)

Julie's comments align with how more than half of UMC applicants described learning from their parents to view informational interviews as a low-pressure way to find interesting positions. They also explained that these interviews allow them to have ample insider knowledge about the team's desired skills and interests, thus allowing them to prepare relevant internship project proposals and to demonstrate their fit with the hiring team during official interviews.

Almost all UMC applicants also characterized informational interviews as a way to secure referrals that are key to getting noticed by prospective hiring managers. These applicants largely view submitting applications through online portals as a waste of time because employers may not even see their applications due to the high volume of submissions. Having a referral thus enables applicants to get on hiring managers' radars and increases their chances of obtaining a formal interview callback. James explained:

"It's important to reach out to chat and get a referral. It's a way to cut through the noise and get an interview....It's pretty standard, so I don't think I'm asking a huge favor." James (UMC, male)

James' perspective was common among UMC applicants. The vast majority of UMC applicants described casual conversations with company employees as a fruitful avenue to gaining referrals and a competitive advantage in the hiring process. These applicants also emphasized feeling comfortable with asking their connections to vouch for their fit with the desired position. As James noted, they talked about this practice as something that is "standard" and not considered a "huge favor."

While most applicants reported using these informal discussions to get and prepare for official interviews, a small minority of UMC applicants also mentioned using informational interviews to circumvent the official interview process as much as possible. Vincent described this strategy: 
"If you know what you want, then you can circumvent the interview process. They'll probably make you go through it to check all the boxes. But, if you know who you want to work with, then you should talk to them....I don't apply for anything anymore. I've purposely set up my life so that I never, ever have to interview for anything because it's stupid." - Vincent (UMC, male)

As a whole, we observe how UMC applicants' class-based value of being at ease with crossing social hierarchy manifests in their comfort with reaching out to close and distant connections, requesting informational interviews, and asking for referrals. This ease results in three reported outcomes for UMC applicants. First, applicants can quickly screen out positions that they view as a poor fit with their research interests and career goals. This tactic prevents them from having to spend extensive time applying for positions they would not want or for which they are not well suited. Second, these applicants can capitalize on the insider information garnered from informal chats to better tailor their preparation for official interviews. Third, applicants can ask for referrals in a way that is not emotionally draining or seen as spending their (or their mentors') social capital.

\subsubsection{Working- and Middle-Class Applicants: Respectful about Relying on Connections}

Like their UMC counterparts, WMC applicants often emphasized the usefulness of social connections in the hiring process. However, WMC applicants across the board described being less comfortable than their UMC counterparts with reaching out to their social networks, even though they know that it is integral to playing the hiring game. These WMC applicants were more likely to describe themselves as deferring to social hierarchy, and they emphasized being respectful about, rather than being at ease with, asking connections for assistance with their internship search. The majority of WMC applicants shared concerns that their requests might burden their contacts, and they expressed a desire to have built up a certain amount of social credit with a person before reaching out. Thus, many WMC applicants focused on leveraging a tight network of close friends or their advisors as well as attending formal recruiting events to build connections with company employees. The majority of WMC applicants in our study described feeling "awkward" or "self-seeking" to the distant connections (i.e., strangers or acquaintances) to whom they felt a pressure to contact. Carson explained how he felt about reaching out to distant contacts:

"If I don't know the person well, then it can feel awkward and self-seeking. But at the same time, it's valuable. So in most cases, I'll ask if I know the person pretty well.... Maybe it comes from the cultural norm that your relationships should be mutually beneficial. My parents taught me to be respectful and not exploit people for personal gains." - Carson (WMC, male)

Like Carson, most WMC applicants characterized leveraging distant contacts for help with their internship applications as uncomfortable but valuable. These applicants explained that while they do feel comfortable leaning on close connections for application support, they feel hesitant to call on more distant contacts. As Carson's comments reflect, many of these WMC applicants were cognizant of the fact that their familial upbringing instilled in them a sense of respect for other's time-which is a hallmark of WMC values [44]-particularly those in a position of power.

Despite their discomfort with reaching out to distant contacts, most WMC applicants recounted the effort they expended to surpass these emotional hurdles. For example, Noel said: 
"I'd want to first get in touch before asking weeks later: 'Now that we're back in touch, I would like to pick your brain about the interview process or pick your brain about what your team is working on.' It's just my style of networking....I'm uncomfortable asking favors out of the blue from people I'm not close with. I find it more natural to get back in touch and maybe find an opportunity to help them out in some way first.... My parents definitely raised me to be a kind person. Like, I value building more of a relationship and helping others first before asking something of them." - Noel (WMC, male)

Here, Noel indicated his baseline discomfort with leveraging connections. However, he emphasized the importance of reaching out and found a style of leveraging connections that does not compromise his personal values; values in which his parents raised him to believe. In this case, Noel described preferring to first reconnect and perhaps find a way to assist the contact before asking for help.

In addition to developing tactics to directly email distant connections, numerous WMC applicants emphasized pursuing official channels (e.g., online resources, career fairs, or introductions by their advisors) to identify potential positions. For example, Oscar found opportunities through listservs:

“[University]'s lists get a bunch of emails about job opportunities. Some people from [company] were doing on-campus interviews for us to learn about [company] and get ready for the internship application season. I went for one, and it went well. That's how my application process started." - Oscar (WMC, male)

Oscar cited two common resources that WMC applicants often used: (a) departmental emails about job opportunities and (b) career fairs or campus recruiting events. Although WMC applicants largely reported being uncomfortable with informally reaching out to strangers, they frequently used these more formal networking opportunities when an implicit invitation was extended. For example, Lydia applied first, then leveraged a connection that became apparent on social media:

"Some guy said on Twitter that his team was hiring. I e-mailed him if I should apply, and he said yes. I filled out my application two months ago and didn't hear back. But when I edited the application saying, 'I want to work with [guy],' they replied the next day: 'We're happy to schedule an interview."' - Lydia (WMC, female)

Lydia's experience reflects how more than three-quarters of WMC applicants hesitate to ask for application support if a potential connection does not actively signal their openness to such requests. In a similar vein, WMC applicants reported talking to insiders only after close friends, advisors, and industry mentors volunteered to introduce applicants to second-degree connections at the company. In short, WMC applicants described wanting direct introductions, clear invitations to contact, or formal recruitment avenues before they felt comfortable reaching out to tertiary contacts. That said, having a strong lab alumni culture that normalizes reaching out to contacts or coming from elite undergraduate institutions that socialize the UMC norms of supportseeking also appears to have an influence on whether or not WMC applicants are comfortable reaching out to distant contacts.

While the majority of UMC applicants described being comfortable deviating from the official hiring process, most WMC applicants reported the opposite. Almost all WMC applicants began their internship search process with formal online applications. This tactic stands in stark contrast 
to UMC applicants' general beliefs that online applications provide a low return on time investment. These different orientations to the formal hiring process suggest that WMC applicants are more likely to assume that hiring mostly happens through a firm's official hiring process and thus spend more time engaged in formal application processes. Dan elaborated:

"Passing the technical interviews doesn't mean I'll get an offer. I'll still need to get matched with a particular project. It's late in the interview season, so there's a good chance that there aren't any projects left for me....I didn't want to apply until I finished solving problems on HackerRank and going through Cracking the Coding Interview. Looking back, I should've just applied earlier to more places." - Dan (WMC, male)

While Dan understood the importance of finding a good project match, he and numerous WMC applicants prioritized getting through the initial interview stages first. WMC applicants' focus on following official hiring processes meant that, unlike UMC applicants who ruled out irrelevant internships early on, WMC applicants relied on later-stage project matching interviews to assess whether or not the internship was a good fit. Focusing on "passing" early-stage interviews meant that when WMC applicants did schedule casual conversations, they were focused on gleaning different information from their company contacts than their UMC counterparts.

While UMC applicants across the board leveraged informational interviews to get insider information on project and team fit information, WMC applicants more often focused on the structural, procedural, or technical aspects of interviews that would help them get past the first stages of interviewing. Ben outlined the information he seeks from friends and online searches and how it contributes to his feelings during the interview:

"The most important questions for me were: 'What was the interview structure? What kinds of questions? How difficult were they?' Feeling more prepared and confident means that I'll be less likely to be anxious and not answer the questions as well....Like, there was once I didn't know what to expect. I got caught off guard and completely forgot how to solve the problem. That was embarrassing. I felt like I wasted the interviewer's time." - Ben (WMC, male)

Ben described the two steps he took to try to understand what would happen in the interview itself: calling upon close contacts to understand the interview structure and searching online to identify the potential types of interview questions. Ben, and numerous WMC applicants, explained that learning as much as possible about what a typical interview might look like alleviated anxiety. They often reported focusing on proving their technical skills (as opposed to projecting team fit or asserting their specific interests) in earlier interviews. As Ben's comment reflects, such behavior also aligned with the values that many WMC applicants described learning from their parents around respecting interviewers' time by being prepared for interviews.

These responses illuminate the degree to which WMC applicants develop coping mechanisms for what they experience as an ambiguous and emotionally taxing interview process. The vast majority of WMC applicants reported that leveraging social ties, especially distant connections, creates feelings of awkwardness and anxiety. These applicants described how they feared reaching out to distant connections and asking them for insider information and/or referrals would come across as presumptuous and entitled. In order to deal with these feelings, most WMC applicants discussed developing complicated strategies to help them navigate an elite hiring context that valorizes UMC cultural norms while simultaneously abiding by their cultural values. 
Again, the contrast between how UMC and WMC applicants experience the job search process was striking. While UMC applicants generally did not express their reservations around reaching out to connections, WMC applicants regularly talked about how much time and energy they put into considering whether it would be appropriate to email a contact. Where UMC applicants focused on informal connections, WMC applicants were much more responsive to formal recruiting and networking processes. Both WMC and UMC applicants used informational interviews to generate insider knowledge about the hiring process. However, UMC applicants focused on revealing hiring team needs, while WMC applicants emphasized learning interview structure and content. Finally, where UMC applicants ruled out uninteresting internships early on, most WMC applicants described spending a substantial amount of time following official hiring procedures, ruling out internships only during later stages of interview processes. These differences, as we discuss next, have compounding effects on the tacit expectation that applicants should project collegiality and collaboration during interviews.

\subsection{Demonstrating Collegiality and Collaboration}

In addition to the expectation that one should call upon social networks to get an interview, both UMC and WMC applicants emphasized the importance of displaying collegiality and collaboration during the interview itself. However, we again observe clear class-based differences in applicants' emotional responses to and tactics for demonstrating collegiality and collaboration in the interview.

\subsubsection{Upper-Middle-Class Applicants: Display of Social Ease with Interviewers and Preference for} Direct Help-Seeking Strategies

The vast majority of UMC applicants described connecting with their interviewers through casual conversations or previous research collaborations before officially applying. As a result of prior interactions, these applicants discussed feeling comfortable during interviews. For example, Kent talked about his typical feelings during interviews:

"I don't feel really anxious during [interviews]. Of course, I want to solve [the problem] or make the interviewer think I'm a good candidate. If I seem super anxious, then the interviewer will be like, 'What's up with this guy?' But I'm not so worried about it for me personally.” - Kent (UMC, male)

As Kent indicated, UMC applicants have a clear desire to make a good impression, but for most of these applicants, this desire does not lead to an anxious reaction. This lack of anxiety enables applicants to behave in interviews as they would during day-to-day professional interactions. In turn, this ease of interaction likely makes it easier for these applicants to make a positive impression on hiring decision-makers.

Across the board, UMC applicants reported a high degree of conversational ease and an ability to facilitate a casual and fun atmosphere during the interviews. Even the few applicants who described feeling nervous about whether the interviewer would be socially awkward explained that this feeling subsided as soon as the interview began. Tess explained:

"Beforehand there were still nerves about 'Are they going to like or hate me? Am I going to say something dumb?' But when I'm in the moment, I'm like 'they are doing cool work' and it's fun.... I definitely learned a lot about how to talk to academics just by osmosis early on from my dad who is a professor... So in the interviews, they all felt like 
researchers, like I know how to fall back on my norms of talking with a professor from another lab.” - Tess (UMC, female)

Over and over, these applicants described leaving an interview feeling confident in their abilities to develop a sense of ease with the interviewer. Like Tess, these applicants also highlighted how they learned these skills from their parents with professional or managerial jobs-positions that require them to communicate in a way that elite employers deem as collegial. In a similar vein, Vincent highlighted how he kept his composure even during a particularly challenging interview:

"Normally I don't have to do anything. I'm like, 'I want this new person to like me, so I'll try to be fun and nice.' Sometimes you're in a really bad mood, or you got no sleep because you flew to [another state] for it the day before. So, you have to drink a cup of coffee, put on your best face and be fun." - Vincent (UMC, male)

Here, Vincent alluded to less-than-ideal circumstances, entering an early morning interview after his flight landed late the night before. Rather than expressing anxiety, stress, or even frustration, Vincent described "putting on [his] best face" for meeting a new person and "being fun." Most notably, he indicated that this interaction style comes naturally to him and that, in his words, he doesn't "have to do anything." Most UMC applicants shared a desire to have fun with interviewers. And even more importantly, these statements suggested a seemingly natural ability to make what could be a stressful experience fun and engaging. Mia, for example, described using humor to connect with interviewers during coding interviews:

"I try to make jokes, like say a funny but technical answer. Or say an outrageous answer, but you only know it's outrageous if you're in on the joke. It's hard to be technical and sarcastic, but I like to do that....Some people prefer to give straightforward answers, but I don't think that's as fun or memorable....But I didn't even consciously think about how I try to crack jokes until you asked me about this." - Mia (UMC, female)

Mia's quotes illustrate how UMC applicants view the use of humor as a valuable way to stand out from other applicants. We also notice that these applicants described using humor instinctively. It was not until speaking with us that Mia realized how much she draws on humor during interviews. As noted above, UMC applicants often connected with their interviewers through informational chats prior to official interviews. Such prior familiarity can engender particularly congenial interviews. Tyler described his interview with hiring managers he had already developed a relationship with:

"We were just laughing the first few seconds of calling them formally in this sense because we were not taking it seriously. I was like, 'Hey, [name],' and just laughing. Since we already knew each other, it was silly that we have to do this formal thing. Immediately after that, we acknowledged that it'd be casual." - Tyler (UMC, male)

Tyler's case is an extreme example in that both the interviewer and interviewee vocalized the casual nature of the interview. While other UMC applicants did not explicitly do so during the hiring interview, they still described their tone in conversation as informal.

The vast majority of UMC applicants also reported being comfortable with directly asking interviewers for assistance during coding interviews. They casually used the interviewer as a 
problem-solving partner without the fear of revealing gaps in their technical skills. Julie outlined the advice she would give to other job seekers:

"In addition to talking out loud, admit early on if you're don't understand something or have a question. I've done this countless times. Like: 'I don't know how to solve this part of the problem....Here are all the possible ways forward. What do you think if I tried this approach?' For me, being honest about what I know and don't know has always made the discussion positive and constructive." - Julie (UMC, female)

Like Julie, the majority of UMC applicants discussed using direct help-seeking tactics, such as asking for feedback on their proposed approach and requesting hints. As prior literature has shown $[8,14]$, it is likely that interviewers at technology companies would interpret applicants' direct help-seeking tactics as being open to collaborating with others and leveraging their expertise to solve problems.

When asked why they feel comfortable with casually interacting with interviewers or directly asking for help, many UMC applicants talked about how their parents taught them to view everyone as equals. Frank described his mother's parenting style and how that influenced his perspectives:

“My parents don't require intense respect. My mom's a doctor. But, she's very casual. She injects into your mind the idea that you're on par with anybody. You shouldn't let anybody treat you as lesser just because you're younger or have less experiences. You're capable of doing anything you want. I think that was really important [in shaping my views]." - Frank (UMC, male)

Together, these stories demonstrate how UMC applicants' reported ease with crossing social hierarchy contributes to their comfort with displaying collegiality and collaboration. Most of these participants used language suggesting that they are "equals" with interviewers and can naturally facilitate casual conversations with interviewers or ask them for help.

\subsubsection{Working- and Middle-Class Applicants: Display of Respect to Interviewers and Preference for Indirect Help-Seeking Strategies}

By contrast, WMC applicants were much more likely than their UMC counterparts to report being nervous both before and during the interviews. Rather than speaking casually and joking with the interviewers, WMC applicants described acting in a way that shows respect to the interviewers. They discussed speaking politely and engaging in general pleasantries.

WMC applicants attempted to use the behavioral interview not only to prove their competence and potential interest in the position but also to glean hints about the team's work priorities (information that most UMC applicants reported having before the formal interview process). WMC applicants often described making a substantial effort to interpret interviewers' questions and expressed their disappointment that behavioral interviews did not allow sufficient time to accomplish these goals. Michelle recounted her experience:

"When talking about the internship research project, I hoped to say my research interests, better understand theirs, and talk about an interesting direction for both parties to pursue. Because I want to know if I should invest the time for this internship.... These [interviews] are only half-hour, so it's difficult to come up with new research ideas and talk about all of that." - Michelle (WMC, female) 
Michelle described a commonly shared problem experienced by WMC applicants: brief behavioral interviews did not allow enough time for applicants to get a sense of the hiring team's work interests; identify whether those interests matched their own goals; and brainstorm project ideas that would be mutually beneficial. This experience stands in stark contrast to that of UMC applicants, who described being able to prepare their responses based on information gleaned from informational interviews.

Unsurprisingly, WMC applicants reported feeling more nervous and stressed throughout the interviews than UMC applicants. WMC applicants such as Oscar described feeling evaluated in a matter that felt exposing:

"I don't know if you can ever go into an interview and feel like you're not being evaluated. Even if they say, 'We're just here to learn about you and for you to learn about us,' you know they're going to form opinions about you. You can't not form opinions about somebody when you talk with them." - Oscar (WMC, male)

In general, WMC applicants were keenly aware that they were being evaluated and thus felt it was challenging to be themselves. WMC applicants were more cognizant of the inherent power dynamics present in interviews than their UMC counterparts. As Oscar indicated, even when interviewers stressed that the conversation was supposed to be casual, "you know they're going to form opinions about you." This extra awareness of the evaluative nature of the interaction led to a more complex interview experience for WMC applicants. These applicants reported trying to mask any outward signs of anxiety while internally quieting nerves in order to focus on the task at hand. For example, Kim described feeling nervous during technical interviews:

“[Managing emotions] is really important. It's something I don't always do well.... Nerves are a huge part of it. Focusing on the stress distracts you from thinking about how to solve the problem." - Kim (WMC, female)

The challenge Kim discussed-managing one's emotions while trying to focus on problemsolving-is a common occurrence for WMC applicants. In essence, WMC applicants found it challenging to manage stress and demonstrate collegiality. Instead of feeling at ease, WMC applicants described displaying collegiality by speaking politely. They also discussed attempting to connect with their interviewers, predominantly through general pleasantries and sending thankyou notes after the interview.

Notably, these strategies are different from the joking and informal behavior that UMC applicants described displaying in interviews. WMC applicants' reported tactics are reminiscent of prior research showing that WMC applicants are socialized to respect power dynamics by being polite and formal when interacting with authorities [11,37,44]. We observe that WMC applicants' strategies for demonstrating collegiality and making connections are based on WMC values and norms. Hugo was particularly articulate and cognizant of the ways in which his upbringing shaped his confidence:

"People who grow up upper-middle-class often have a natural confidence about them because they've never suffered setbacks. Whereas if you're a poor minority kid from the bad part of town, and teachers doubt you and people make fun your whole life-even if you have an upward trajectory, it's very hard to project that 'I deserve to be here' attitude. I grew up poor, and I do think like that.” - Hugo (WMC, male) 
Although Hugo has "made it" at one of the highest levels of educational attainment (pursuing a Ph.D. at an elite institution), he still found it challenging to project an "I deserve to be here" attitude. Hugo's is not an isolated case. Numerous WMC applicants described tensions between being technically competent and trusting that others viewed them as technically competent.

In response to these tensions, the majority of WMC applicants described being concerned that asking for help would reveal holes in their technical acumen and reflect poorly on them as applicants. Their views stand in contrast to their UMC counterparts' reported assumption that they are on fairly equal standing with their interviewers and thus feel comfortable soliciting help. All applicants we spoke with displayed an awareness that it is important to express one's thought process, treat the interviewer as a collaborator, and demonstrate technical skills during coding interviews. Knowing that the interview was supposed to be a collaborative experience, most WMC applicants reported eliciting help in an indirect manner that still affirmed their technical competence. They also expressed that being receptive to the interviewer's guidance allowed them to demonstrate an openness to collaboration. Sophia explained:

"I first try to solve the problems on my own. If I get stuck, I'll say, 'In real life, I'll put a comment here and try to find the answer online.' or 'I'll move forward with this idea.'... Then if [the interviewer] sees that you're not in the right direction, they'll kind of present to you another idea. And I'll be like, 'That's really good. I didn't think of that.' to reassure them that I can take feedback in what I'm doing and redirect myself. This shows that I can work in a group setting." - Sophia (WMC, female)

Sophia later described how her parents' perspectives shaped her ideas around indirect helpseeking tactics during interviews:

"My parents, and especially my mom, raised me to be very independent so that wherever I go, I can overcome any obstacles that arise.... So, when in the interview process, I wouldn't [ask for help] right away. That's not the best thing to do because you might present yourself as someone who is going to need a lot of help. And I think it can be disrespectful of their time if you're not even trying." - Sophia (WMC, female)

Like Sophia, numerous WMC applicants reported similar tactics for indirectly asking interviewers for hints. These applicants described demonstrating collaboration through incorporating any hints that interviewers gave. Here, we see how WMC applicants' reported desire to respect authority figures' time translates to their preference for using indirect helpseeking tactics during interviews. We also observe how this desire can stem from the class-based norms that they learn from their familial upbringing.

Many WMC applicants described that while some interviewers could identify and address their indirect requests for help, other interviewers might not be able to. As Lydia commented:

"I was talking through the problem for 10 minutes and the interviewer didn't say anything about me doing it wrong. But it was like, 'Why wouldn't you correct me?' That was frustrating." - Lydia (WMC, female)

Lydia's remarks reveal that interviewers who operate with a different set of norms regarding help-seeking may not be aware of WMC applicants' indirect approach to getting assistance. This mismatch in norms can lead to a stressful interview experience for these applicants. 


\subsection{Working- and Middle-Class Applicants: Learning to Engage in Elite Cultural Contexts}

These data provide examples of how UMC and WMC applicants from elite universities are aware of the same tacit expectations about how to apply for and get elite internships. These data also show that these applicants act on these expectations differently. The vast majority of WMC applicants talked about feeling hesitant about reaching out to all possible social connections and writing cold emails. These applicants also generally described feeling anxious and avoiding directly asking for help during technical interviews.

However, a small number of WMC applicants reported feeling comfortable with displaying collegiality and collaboration in the same style as UMC applicants. Strikingly, all of these WMC applicants had attended elite undergraduate institutions and actively discussed the process of learning to operate in elite contexts over time. Several of these applicants acknowledged that scenarios like the interview process used to be more stressful but that they had improved in their ability to act informally, ask for help, and engage with authority figures in a more collaborative manner. For example, Danielle, a late-stage Ph.D. student who attended an elite undergraduate institution, described learning to share when she did not understand her interviewer's comments or questions by observing others enact this norm:

'I've observed other people who are great at saying, 'I don't know.' It's hard to do earlier in your career because you think you should know everything. But then you realize that no one knows everything. Seeing my PIs ask for clarification at a talk is helpful....That's easier said than done. Sometimes I'm still in conversations where I get $70 \%$ of it, but I'm faking the other $30 \%$, hoping that it'll become clear." - Danielle (WMC, female)

These data suggest that while it can be difficult for WMC students to feel fully comfortable engaging in ways that are the norm for UMC students, WMC students can learn to enact UMC norms over time through repeated exposure to elite contexts. These findings are consistent with prior studies that show how WMC undergraduate students can adopt the dominant norms of their contexts [13,32]. Some WMC applicants who did not attend elite undergraduate universities also described learning to activate cultural scripts aligned with UMC values as Ph.D. students. However, as cultural sociologists assert [32], adopting a new set of cultural codes takes time. It is noteworthy that those few WMC applicants who displayed an awareness and willingness to mimic UMC patterns of behavior were in the later years of their Ph.D. program.

\section{DISCUSSION}

This research unpacks how Ph.D. students studying computer science at elite universities experience the process of applying for prestigious internships in established technology companies. We find that all applicants in our study, regardless of social class background, were aware of two tacit hiring expectations: (a) being willing to leverage social connections to learn more about internship opportunities and (b) demonstrating collegiality and collaboration with interviewers. This finding suggests that universities are successfully sharing tacit rules of hiring with applicants from across social class backgrounds.

However, while WMC and UMC applicants displayed an understanding of these tacit expectations around hiring, they reported dramatically different emotional experiences and described differing application tactics. First, most WMC applicants reported feeling pressured to respect distant connections' time and being less comfortable asking contacts for referrals and an insider's view of the position. As a result, they invested substantial time and energy in learning 
about and applying for positions through official channels. Second, the majority of WMC applicants described displaying collegiality by managing their stress during interviews and being polite with the interviewers. These applicants took on the additional emotional work needed to engage with hiring decision-makers in these elite contexts. Third, numerous WMC applicants discussed not wanting to burden authority figures and avoiding directly asking for help during the interview process.

Our participants' descriptions of their upbringing and prior sociological literature help shed light on how applicants' social class backgrounds shape contrasting emotional experiences and application tactics. Specifically, Table 2 summarizes how applicants use different tactics that are based on their social class values in their attempts to meet employers' hiring expectations.

Building on past studies [11,37], we find that social class values also shape students' interactions with authority figures outside of the school setting, and in this case, when Ph.D. students with the same resources (e.g., understanding of tacit expectations in the job search process and access to professional networks) compete for elite jobs. Many UMC applicants explained that their parents taught them to view everyone, including authority figures such as interviewers and hiring managers, as equals. They described that such coaching encouraged them to be comfortable with asking distant connections at the company (e.g., senior employees, interviewers, and hiring managers) for job search assistance and to feel at ease with demonstrating collegiality and collaboration during interviews. By contrast, most WMC applicants reported learning from their parents to take heed of authority figures' time and energy. These applicants discussed not wanting to burden distant contacts at the company with their requests for what these applicants viewed as too much support when it had not been explicitly offered. These applicants also expressed their desire to be respectful of the power dynamics and emphasized their preference to indirectly ask for help during hiring interviews.

Table 2. Summary of applicants' class-based application tactics

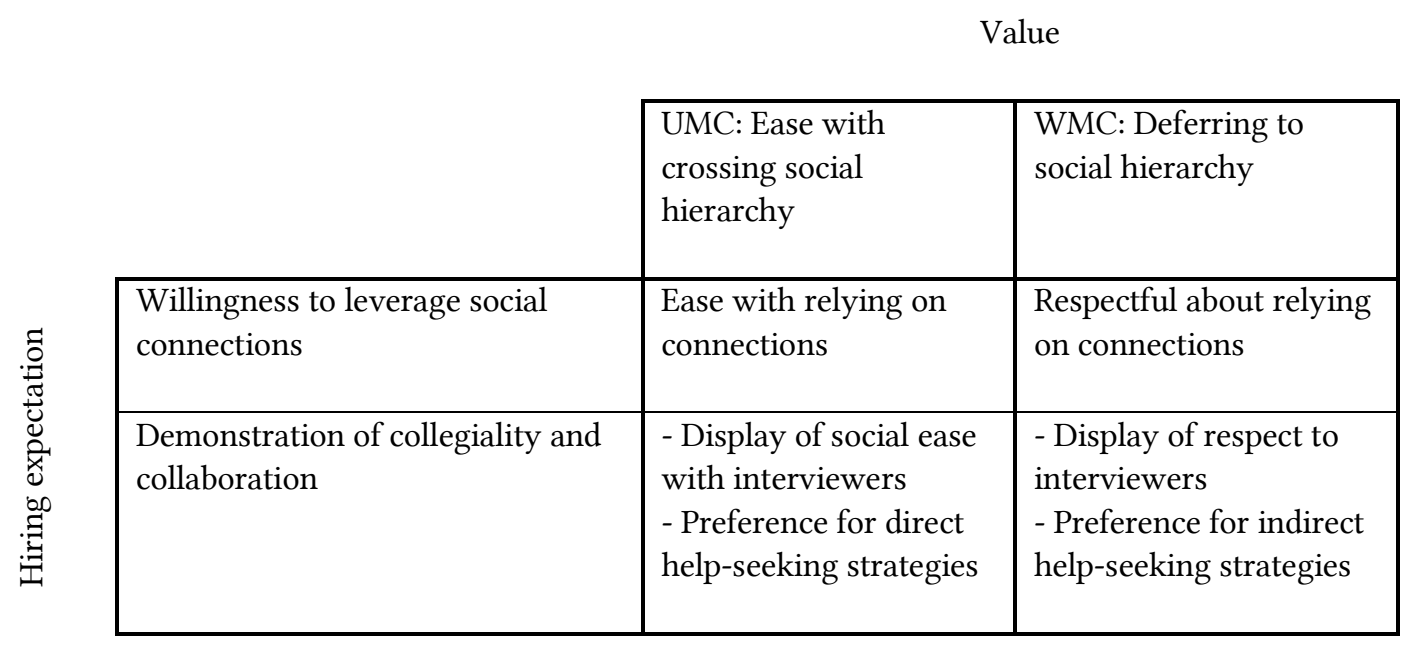

\subsection{Implications for CSCW Literature and Design Implications for Hiring}

Our findings advance scholars' understanding of the unique challenges that WMC applicants face when navigating the hiring process. Current $\mathrm{CSCW}$ and sociological literature on hiring suggests that job seekers from less class-privileged backgrounds face difficulties getting insider coaching 
and referrals because they do not have social connections at the company [14,17,42,47]. Our research adds nuance to this argument. While WMC applicants in our study describe knowing people at prestigious companies, many report feeling uncomfortable asking them for favors if applicants are not close connections or if they have not been explicitly invited to do so. We thus see that WMC applicants' hesitancy around tapping their professional networks may not stem from a lack of social capital but instead from a misalignment between cultural values and current expectations.

In addition, our study speaks to CSCW and sociological research that assumes that less classprivileged job seekers might struggle to get hired because they do not know the unwritten rules of the hiring game $[12,14,42,47]$. This body of literature implies that making visible these unsaid expectations would fully ease job seekers' application process. Our findings challenge this assumption. For example, while WMC applicants understand the importance of appearing confident during the interviews, we observe them doing additional emotional work in two ways. First, they contend with past experiences of classism and manage the anxiety and stress associated with feeling evaluated in predominantly UMC contexts. Second, they actively develop tactics to display what a different social class context views as confidence and collegiality. Thus, merely helping WMC applicants to uncover the hidden curriculum is an insufficient step toward greater equity in hiring, especially if applicants' cultural norms clash with the dominant hiring norms.

Our findings of the class-based differences in applicants' norms and tactics for fulfilling hiring expectations also have implications for design. We agree with previous CSCW and HCI studies that helping applicants identify connections at potential workplaces is a key step toward empowering them [52]. Prior scholars have called for social networking sites to enable applicants to find contacts at companies from whom they could get referrals and information about job opportunities [52]. However, based on our findings, we expand on this suggestion and urge designers to think beyond the question of whether less class-privileged applicants have access to the "right" social connections. We call for additional and necessary steps to ease applicants' burdens of reaching out to social networks.

Hui and colleagues have recently taken on this challenge by designing and evaluating IntroAssist, a tool that reduces users' anxiety about asking professional connections for assistance [30]. IntroAssist achieves this goal by increasing users' skills in writing requests. In addition to these efforts, our findings reveal the need for designers to facilitate applicants' ease with seeking assistance by also considering their class-based norms. We find that at the graduate level, WMC applicants' reservations around seeking help seem to stem more from their class-based value of respecting other people's time than from their lack of writing skills.

Although networking sites (e.g., LinkedIn, Facebook, and Twitter) enable applicants to identify social contacts at potential workplaces, WMC applicants may not feel comfortable asking them for help because they do not want to burden these contacts with requests. To support these applicants, designers of networking sites could allow users to signal on their profiles if they are willing to help their social connections navigate the job search process. This feature would align with WMC applicants' value of respecting other people's time, allowing applicants to feel comfortable reaching out to those who have already indicated an openness to volunteering their time.

As with all designs, designers should consider and examine the potential unintended consequences of implementing the features suggested above. Given that there tend to be fewer employees from less class-privileged backgrounds at prestigious companies, WMC employees might feel pressured to indicate a willingness to mentor and/or be expected to take on an unreasonable share of mentoring work. In addition, employees' public signals of availability might lead them to face an unsustainable number of applicants asking for mentorship. 


\subsection{Implications for Universities, Educators, and Employers}

While our study focuses on WMC applicants at elite universities who are applying for positions at technology companies, prior research suggests that WMC applicants from non-elite universities face similar emotional experiences when competing for jobs at institutions that favor UMC norms [42]. As such, our findings have implications for (a) how a broad range of universities and educators can support applicants' job search process and (b) how employers can reduce classbased inequalities in hiring.

\subsubsection{Implications for Universities and Educators}

Universities and educators play integral roles in enabling students to fulfill hiring expectations. In particular, they provide students with robust social networks through maintaining alumni connections, hosting networking events, and facilitating introductions. They also help students to uncover the hidden curriculum of hiring through organizing job preparation workshops and advising students on their job search strategies. However, our research suggests that merely providing social capital and insider knowledge about the hiring process is insufficient. Universities and educators should recognize that students' social class cultures influence their application experiences and should consider whether WMC students feel comfortable leveraging these social and cultural resources. Our findings further suggest that universities and educators can take steps to ease WMC students' process of using these resources to meet the hiring criteria.

One of the ways that universities and educators could support applicants is through the creation of spaces for WMC students to engage with fellow WMC students and alumni and explore how they can fulfill the hiring expectations. Universities could establish affinity groups and mentorship programs for WMC students. Educators could introduce WMC students to students from similar social class backgrounds who have successfully received a job offer from elite firms. Engaging with WMC peers can enable WMC applicants to gain social support and identify potential ways to minimize the emotional burdens of navigating elite hiring contexts.

Universities could also create alumni directories that allow alumni to indicate if they are open to helping students navigate particular aspects of the job search process. For example, alumni could state if they are willing to do mock interviews, share their experiences at the company, or brainstorm ways to approach the hiring process. Universities could also provide email templates or samples for students to use when reaching out to these contacts. Further, educators could encourage their students to identify and cold email potential hiring managers. Given their familiarity with their students' work and interests, advisors could offer to give feedback on students' cold email drafts to increase students' comfort levels around sending these emails.

\subsubsection{Implications for Employers}

In attempts to increase the diversity of their workforce, companies have launched multiple initiatives to support marginalized applicants, such as women and racially minoritized groups, as they navigate the hiring process [1,21-24]. Examples of such initiatives include organizing diversity recruitment programs [22,24] and ensuring that hiring decision-makers complete unconscious bias training [1,21,23]. We applaud employers' efforts to reduce gender and racial inequality in hiring. As our findings show that applicants' social class background critically shapes their application experiences, we call for employers to also consider this often sidelined but important dimension when diversifying new hires.

To start, elite firms should consider the extent to which applicants feel comfortable leveraging connections. From a practical standpoint, firms can help to connect WMC applicants with mentors 
from similar social class backgrounds who can support them throughout the hiring process. Regarding the expectation that a successful interview is one where the applicant displays effortless confidence and collegiality, interviewers should understand that interviews can be especially stressful for interviewees without class-based advantages. As interviewers enjoy certain degrees of freedom in determining the structure of their interviews, they could help to create a welcoming environment for applicants by inviting questions and making clear the interview structure whenever possible. For example, if applicable, interviewers could let interviewees know ahead of time the kinds of research directions they are interested in discussing so that interviewees can prepare accordingly.

In addition, interviewers should be cognizant of the ways in which applicants enact class-based help-seeking tactics. Our findings show that UMC applicants feel comfortable with directly requesting support (e.g., "I don't know how to do this; can you help me?"). By contrast, WMC applicants prefer to indirectly ask for assistance (e.g., "Here are potential ways of solving the problem [and then pausing to see the interviewers' response]" and "I'm feeling nervous."). As such, interviewers could learn to recognize the different forms of support-seeking and assist applicants accordingly.

\subsection{Limitations and Future Directions}

This study focuses on the role of social class background in shaping applicants' experiences of the hiring process. Ideally, we would have taken an intersectional approach toward understanding how U.S. applicants' social class background, race, gender, and familial immigrant status influence their experiences. However, like other sociological studies [10,11], the logistical challenges of getting the diverse sample needed led us to focus on participants' social class background. We also did not recruit any international students in order to focus on how socioeconomic structures in the U.S. shape students' application experiences and tactics.

That said, our research suggests that WMC women face a "double bind" in hiring; they not only experience gender discrimination but also must develop tactics to respond to UMC hiring norms. Further, as past research finds that Black women face substantial racial and gender discrimination $[15,40]$, it is plausible that WMC Black women applicants encounter a "triple bind" in navigating predominantly white, male, and UMC labor markets. Finally, prior studies suggest that compared to their counterparts from similar racial, gender, and social class backgrounds, recently immigrated students who are less familiar with UMC cultural norms in the U.S. might be more hesitant and formal when interacting with authority figures [11]. Echoing CSCW and HCI scholars [43], we thus call for future research to examine how applicants' social class background, race, gender, and immigration experiences intersect when competing for prestigious occupations.

In addition, we encourage future work to examine with more specificity how WMC students are enculturated into the dominant UMC values that characterize elite universities and firms. This study focuses on the role of students' social class background, which is closely tied to their familial upbringing, in shaping students' class-based values. Yet, schools are also a site of social class socialization that can either perpetuate or disrupt the norms that students initially learn in the home setting [44]. As such, scholars could examine the potential barriers that WMC students might experience in aligning their cultural values with the expectations and assumptions embedded in elite contexts. 


\section{CONCLUSION}

Current literature suggests that WMC students who get admitted into Ph.D. programs at elite institutions have "made it"-that, as attendees of elite institutions with ample resources, they will enjoy the same hiring opportunities and experiences as applicants who grew up in UMC families. While we are relieved to report that our work suggests that these students do enjoy access to similar resources (in terms of social connections and insider knowledge about employers' expectations), we also find that their emotional experiences and tactics regarding these resources vary along social class lines. Specifically, WMC applicants must contend with hiring practices grounded in UMC norms. These applicants do so successfully and, in our study, enjoy the same hiring rates as their UMC counterparts. However, we find that WMC applicants spend substantial amounts of time applying for jobs, and they do extensive emotional work to enact hiring expectations. The increased time as well as emotional and mental energy that WMC applicants report spending on the application process is substantial. Understanding and addressing these differences will contribute to technology companies' ongoing efforts to diversify the technology workforce. It will also align with universities and educators' longstanding endeavors to support student applicants through the hiring process. We thus urge employers, universities, and educators in predominantly UMC workplace cultures to consider social class alongside race and gender in their diversity, equity, and inclusion initiatives.

\section{ACKNOWLEDGMENTS}

This paper is based upon work supported by the National Science Foundation under Grant No. DGE-1920519. We would like to thank our research participants for sharing their thoughts and experiences with us. We also thank the ACs, anonymous reviewers, Colette Brown, Caitlyn Fong, Elisabeth Ivey, Sharon Koppman, and Katie Turner for their insightful feedback on this paper.

\section{REFERENCES}

[1] Amazon. 2019. Building an inclusive culture. About Amazon. Retrieved January 3, 2020 from https://www.aboutamazon.com/working-at-amazon/diversity-and-inclusion/building-an-inclusive-culture

[2] Arthur G Bedeian, David E Cavazos, James G Hunt, and Lawrence R Jauch. 2010. Doctoral degree prestige and the academic marketplace: A study of career mobility within the management discipline. Academy of Management Learning \& Education 9, 1 (2010), 11-25.

[3] Mahnaz Behroozi, Alison Lui, Ian Moore, Denae Ford, and Chris Parnin. 2018. Dazed: measuring the cognitive load of solving technical interview problems at the whiteboard. 93-96.

[4] Mahnaz Behroozi, Shivani Shirolkar, Titus Barik, and Chris Parnin. 2020. Debugging Hiring: What Went Right and What Went Wrong in the Technical Interview Process.

[5] Amy J. Binder, Daniel B. Davis, and Nick Bloom. 2016. Career Funneling: How Elite Students Learn to Define and Desire "Prestigious"' Jobs. Sociol Educ 89, 1 (January 2016), 20-39. DOI:https://doi.org/10.1177/0038040715610883

[6] Jennie E Brand and Charles N Halaby. 2006. Regression and matching estimates of the effects of elite college attendance on educational and career achievement. Social Science Research 35, 3 (2006), 749-770.

[7] Virginia Braun and Victoria Clarke. 2006. Using thematic analysis in psychology. Qualitative Research in Psychology 3, 2 (January 2006), 77-101. DOI:https://doi.org/10.1191/1478088706qp063oa

[8] Alison Wood Brooks, Francesca Gino, and Maurice E. Schweitzer. 2015. Smart People Ask for (My) Advice: Seeking Advice Boosts Perceptions of Competence. Management Science 61, 6 (June 2015), 1421-1435. DOI:https://doi.org/10.1287/mnsc.2014.2054

[9] David K Brown. 2001. The social sources of educational credentialism: Status cultures, labor markets, and organizations. Sociology of education (2001), 19-34. 
[10] Jessica McCrory Calarco. 2014. Coached for the Classroom: Parents' Cultural Transmission and Children's Reproduction of Educational Inequalities. Am Sociol Rev 79, 5 (October 2014), 1015-1037. DOI:https://doi.org/10.1177/0003122414546931

[11] Jessica McCrory Calarco. 2018. Negotiating opportunities: How the middle class secures advantages in school. Oxford University Press.

[12] Jessica McCrory Calarco. 2020. A Field Guide to Grad School: Uncovering the Hidden Curriculum. Princeton University Press.

[13] Prudence L Carter. 2005. Keepin'it real: School success beyond Black and White. Oxford University Press.

[14] Phoebe K. Chua and Melissa Mazmanian. 2020. Are You One of Us?: Current Hiring Practices Suggest the Potential for Class Biases in Large Tech Companies. In Proceedings of the ACM on Human-Computer Interaction, New York. DOI:https://doi.org/10.1145/3415214

[15] Kimberlé W Crenshaw. 2017. On intersectionality: Essential writings. The New Press.

[16] Daniel Davis and Amy Binder. 2019. Industry, Firm, Job Title: The Layered Nature of Early-Career Advantage for Graduates of Elite Private Universities. Socius 5, (January 2019), 2378023119859711. DOI:https://doi.org/10.1177/2378023119859711

[17] Tawanna R. Dillahunt. 2014. Fostering social capital in economically distressed communities. In Proceedings of the SIGCHI Conference on Human Factors in Computing Systems (CHI '14), Association for Computing Machinery, New York, NY, USA, 531-540. DOI:https://doi.org/10.1145/2556288.2557123

[18] Tawanna R Dillahunt, Vaishnav Kameswaran, Linfeng Li, and Tanya Rosenblat. 2017. Uncovering the values and constraints of real-time ridesharing for low-resource populations. ACM, 2757-2769.

[19] Tawanna R. Dillahunt and Alex Lu. 2019. DreamGigs: Designing a Tool to Empower Low-Resource Job Seekers. In Proceedings of the 2019 CHI Conference on Human Factors in Computing Systems (CHI '19), ACM, New York, NY, USA, 578:1-578:14. DOI:https://doi.org/10.1145/3290605.3300808

[20] Tawanna R Dillahunt and Amelia R Malone. 2015. The promise of the sharing economy among disadvantaged communities. ACM, 2285-2294.

[21] Facebook. 2018. Workplace by Facebook. Workplace by Facebook. Retrieved May 1, 2018 from https://www.facebook.com/workplace

[22] Facebook. 2019. Facebook 2019 Diversity Report: Advancing Diversity and Inclusion. Facebook Newsroom. Retrieved September 19, 2019 from https://newsroom.fb.com/news/2019/07/2019-diversity-report/

[23] Google. 2014. You don't know what you don't know: How our unconscious minds undermine the workplace. Official Google Blog. Retrieved September 18, 2019 from https://googleblog.blogspot.com/2014/09/you-dontknow-what-you-dont-know-how.html

[24] Google. 2019. Google Diversity Report 2019. Google Diversity. Retrieved September 19, 2019 from https://diversity.google/annual-report/

[25] Michael Hadani, Susan Coombes, Diya Das, and David Jalajas. 2012. Finding a good job: Academic network centrality and early occupational outcomes in management academia. Fournal of Organizational Behavior 33, 5 (2012), 723-739. DOI:https://doi.org/10.1002/job.788

[26] Phillip Hall Jr and Kinnis Gosha. 2018. The Effects of Anxiety and Preparation on Performance in Technical Interviews for HBCU Computer Science Majors. In Proceedings of the 2018 ACM SIGMIS Conference on Computers and People Research, 64-69.

[27] David G. Hendry, Norah Abokhodair, Rose Paquet Kinsley, and Jill Palzkill Woelfer. 2017. Homeless Young People, Jobs, and a Future Vision: Community Members' Perceptions of the Job Co-op. In Proceedings of the 8th International Conference on Communities and Technologies (C\&T '17), ACM, New York, NY, USA, 22-31. DOI:https://doi.org/10.1145/3083671.3083680

[28] Karen Ho. 2009. Liquidated: An Ethnography of Wall Street. Duke University Press.

[29] Joey Chiao-Yin Hsiao and Tawanna R. Dillahunt. 2018. Technology to Support Immigrant Access to Social Capital and Adaptation to a New Country. Proc. ACM Hum.-Comput. Interact. 2, CSCW (November 2018), 70:1-70:21. DOI:https://doi.org/10.1145/3274339

[30] Julie S. Hui, Darren Gergle, and Elizabeth M. Gerber. 2018. IntroAssist: A Tool to Support Writing Introductory Help Requests. In Proceedings of the 2018 CHI Conference on Human Factors in Computing Systems. Association for Computing Machinery, New York, NY, USA, 1-13. Retrieved July 4, 2021 from https://doi.org/10.1145/3173574.3173596

[31] Julie Hui, Kentaro Toyama, Joyojeet Pal, and Tawanna Dillahunt. 2018. Making a Living My Way: Necessitydriven Entrepreneurship in Resource-Constrained Communities. Proc. ACM Hum.-Comput. Interact. 2, CSCW (November 2018), 71:1-71:24. DOI:https://doi.org/10.1145/3274340 
[32] Anthony Abraham Jack. 2019. The privileged poor: How elite colleges are failing disadvantaged students. Harvard University Press.

[33] Shamus Rahman Khan. 2010. Privilege: The Making of an Adolescent Elite at St. Paul's School. Princeton University Press.

[34] Paul W Kingston and John C Smart. 1990. The economic pay-off of prestigious colleges. The high status track: Studies of elite schools and stratification (1990), 147-174.

[35] Sharon Koppman. 2016. Different Like Me: Why Cultural Omnivores Get Creative Jobs. Administrative Science Quarterly 61, 2 (June 2016), 291-331. DOI:https://doi.org/10.1177/0001839215616840

[36] Michèle Lamont. 2009. How professors think: inside the curious world of academic judgment. Harvard University Press, Cambridge, Mass.

[37] Annette Lareau. 2003. Unequal Childhoods: Class, Race, and Family Life. University of California Press.

[38] Gayle Laakmann McDowell. 2019. Cracking the coding interview: 189 programming questions and solutions. CareerCup.

[39] Ihudiya Finda Ogbonnaya-Ogburu, Kentaro Toyama, and Tawanna R. Dillahunt. 2019. Towards an Effective Digital Literacy Intervention to Assist Returning Citizens with Job Search. In Proceedings of the 2019 CHI Conference on Human Factors in Computing Systems (CHI '19), ACM, New York, NY, USA, 85:1-85:12. DOI:https://doi.org/10.1145/3290605.3300315

[40] Mark Pogrebin, Mary Dodge, and Harold Chatman. 2000. Reflections of African-American women on their careers in urban policing. Their experiences of racial and sexual discrimination. international fournal of the Sociology of law 28, 4 (2000), 311-326.

[41] Lauren A. Rivera. 2011. Ivies, extracurriculars, and exclusion: Elite employers' use of educational credentials. Research in Social Stratification and Mobility 29, 1 (January 2011), 71-90. DOI:https://doi.org/10.1016/j.rssm.2010.12.001

[42] Lauren A. Rivera. 2016. Pedigree: How Elite Students Get Elite fobs. Princeton University Press.

[43] Ari Schlesinger, W. Keith Edwards, and Rebecca E. Grinter. 2017. Intersectional HCI: Engaging Identity Through Gender, Race, and Class. In Proceedings of the 2017 CHI Conference on Human Factors in Computing Systems (CHI '17), ACM, New York, NY, USA, 5412-5427. DOI:https://doi.org/10.1145/3025453.3025766

[44] Nicole M. Stephens, Hazel Rose Markus, and L. Taylor Phillips. 2014. Social Class Culture Cycles: How Three Gateway Contexts Shape Selves and Fuel Inequality. Annual Review of Psychology 65, 1 (2014), 611-634. DOI:https://doi.org/10.1146/annurev-psych-010213-115143

[45] Jenny M. Stuber. 2009. Class, Culture, and Participation in the Collegiate Extra-Curriculum. Sociological Forum 24, 4 (2009), 877-900. DOI:https://doi.org/10.1111/j.1573-7861.2009.01140.x

[46] Deborah M. Warnock and Sara Appel. 2012. Learning the Unwritten Rules: Working Class Students in Graduate School. Innov High Educ 37, 4 (August 2012), 307-321. DOI:https://doi.org/10.1007/s10755-011-9204$\mathrm{X}$

[47] Earnest Wheeler and Tawanna R. Dillahunt. 2018. Navigating the Job Search As a Low-Resourced Job Seeker. In Proceedings of the 2018 CHI Conference on Human Factors in Computing Systems (CHI '18), ACM, New York, NY, USA, 48:1-48:10. DOI:https://doi.org/10.1145/3173574.3173622

[48] Jill Palzkill Woelfer and David G. Hendry. 2010. Homeless Young People's Experiences with Information Systems: Life and Work in a Community Technology Center. In Proceedings of the SIGCHI Conference on Human Factors in Computing Systems (CHI '10), ACM, New York, NY, USA, 1291-1300. DOI:https://doi.org/10.1145/1753326.1753520

[49] Jill Palzkill Woelfer and David G. Hendry. 2012. Homeless Young People on Social Network Sites. In Proceedings of the SIGCHI Conference on Human Factors in Computing Systems (CHI '12), ACM, New York, NY, USA, 2825-2834. DOI:https://doi.org/10.1145/2207676.2208686

Received October 2020, revised April 2021, accepted July 2021. 